\title{
Validation of Key Parameters Between Real and Computer Model of Suspension System Used in FSAE Vehicle
}

\author{
Krzysztof Ziemba', Jan Tracz' ${ }^{1}$, Witold Rządkowski ${ }^{*}$, Michał Kowalik' \\ 1 Warsaw University of Technology, Institute of Aeronautics and Applied Mechanics, Nowowiejska 24, \\ 00-665 Warsaw, Poland \\ *Corresponding author's e-mail: witold.rzadkowski@pw.edu.pl
}

\begin{abstract}
The aim of this paper was to determine the differences in the designed and manufactured model of a suspension. A set of key parameters was compared, including camber and toe in angles and their change w.r.t wheel travel, as well as the motion ratio. It also focused on the possibility of accurately determining the suspension system kinematics using affordable measuring devices available on the market. First, the design process, main goals and project assumptions were briefly described. Next, the CAD model and manufacturing process was presented. Finally, the measurements of both computer and real model were performed. The obtained results were compared and a significant difference between models was observed. The reason of such variation could not be determined unambiguously, as there were numerous factors that could potentially influence the results. Moreover, it was proven that accurate determination of kinematics is impossible using the given set of measuring devices.
\end{abstract}

Keywords: multi-link suspension system, validation, vehicle kinematics, FSAE

\section{INTRODUCTION}

FSAE, or Formula SAE is a student engineering competition organized by Society of Automotive Engineers (SAE). It is held as international competition for University students who have to design, build and compete with a special formula vehicle. Designing a race car suspension system for track racing at FSAE events has two main aspects: lightweight construction and effective operation. A representative of such vehicle is WUT2, designed by students at WUT Racing Team, a student's association of Warsaw University of Technology, which has participated in the competition series since 2011. Other designs were presented in $[1,3,10]$.

When modeling the next (third) vehicle, a question had been raised, whether the manufactured suspension system has relatively similar parameters to the one modeled in computer aided design (CAD). In order to verify this, the following study was performed. The test subject was the suspension system of the former vehicle (WUT2). This was also the test of affordable (for a student organization) measuring equipment. Some general rules about the measurement techniques were presented in [2] and [7]. There were other approaches to the validation of suspension operation made by [12], yet only by FEM. Additionally, some teams measure the influence of chassis stiffness on the suspension operation.

\section{Parametric model preparation}

The first step of the design process was to prepare the 3D parametric model, which uses characteristic parameters (Table 1) to create the geometry of the suspension system in the default state. The design is restricted by competition rules book, issued by SAE International. The rules regulate the safety of the system. The second design restriction is the type of suspension system used i.e. multi-link suspension with shock absorbers in the push rod configuration, which suits best for 
Table 1. Parameters used in design process, more details at [4]

\begin{tabular}{|l|l|}
\hline \multicolumn{1}{|c|}{ Parameter } & \multicolumn{1}{c|}{ Effect } \\
\hline Roll center & $\begin{array}{l}\text { Changes unsprung mass transfer } \\
\text { between shock absorbing system } \\
\text { and wishbones }\end{array}$ \\
\hline $\begin{array}{l}\text { Camber and caster } \\
\text { angle }\end{array}$ & $\begin{array}{l}\text { Influences tire deflection, which } \\
\text { has an impact on friction coefficient } \\
\text { between the tire and ground }\end{array}$ \\
\hline $\begin{array}{l}\text { King pin inclination } \\
\text { and mechanical trail }\end{array}$ & $\begin{array}{l}\text { Influences the magnitude of turning } \\
\text { moment acting on the wheel } \\
\text { resulting from existing lateral force }\end{array}$ \\
\hline Scrub radius & $\begin{array}{l}\text { Influences the magnitude of turning } \\
\text { moment acting on the wheel } \\
\text { resulting from existing longitudinal } \\
\text { force }\end{array}$ \\
\hline Wheel base & $\begin{array}{l}\text { Changes the mass distribution during } \\
\text { turning, braking and accelerating. }\end{array}$ \\
\hline Longitudinal tilt axis & $\begin{array}{l}\text { Changes the unsprung mass transfer } \\
\text { at the front and rear axle during } \\
\text { braking and accelerating }\end{array}$ \\
\hline Ackerman angle & Determines the slip angle \\
\hline
\end{tabular}

this vehicle. Other choices included the pull rod configuration, which were used in the past in race cars, yet due to many disadvantages of this solution, it was not used. The details of its operation were described in [6].

Another important factor is that some of the parts must be bought, due to the economic reasons. It includes tires, rims, steering gear and shock absorbers. On the basis of those parameters and performed calculations, the parametric model was created. It represents the suspension system as a simple set of mounting points allocated in space. During the measurements performed in this study, some of them were measured including camber and toe in angles (Figure 1 and Figure 2)

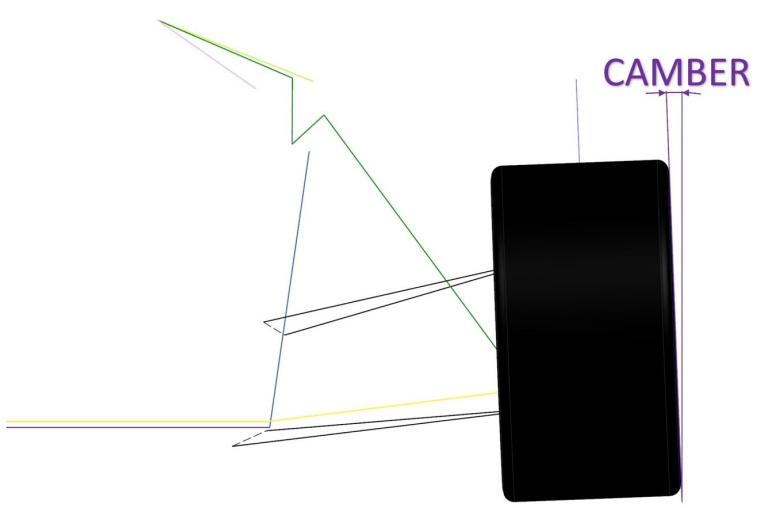

Fig. 1. Parametric model of the front suspension with camber angle

\section{Numerical and dynamical analysis in quasi- static state}

The second stage of the design process was focused on creating multi body dynamics structure of a suspension system based on a parametric model. The crucial parameters in the simplified, nominal model are:

- change of camber angle as a function of wheel travel

- change of toe in angle as a function of wheel travel

- resulting motion ratio (defined as ratio of wheel travel to shock absorber spring deflection)

The results of the analysis were prepared in NX Unigraphics Motion module and the results were transferred to the .csv files that were later combined with the measurements performed on a real model. The maximum deflection of shock absorber spring is equal to $57 \mathrm{~mm}$. The wheel travel has the same value as the design motion ratio is equal to unity. The gathered data enabled to create a dynamic model prepared in Optimum-G spreadsheet for the calculations of the vehicles in a quasi-static state (Table 2) with accurate tire data. The model that could be validated easily is an oval lap with constant speed. The geometry of such an oval was taken from FSAE "ski-pad" test described in the regulations (Fig. 3) lapped in 6s, which results in $1 \mathrm{G}$ of lateral force.

\section{CAD/CAM/CAE model of suspension}

The ultimate design stage consisted of creating the model in CAD software that is based on the parametric and geometric model as well as

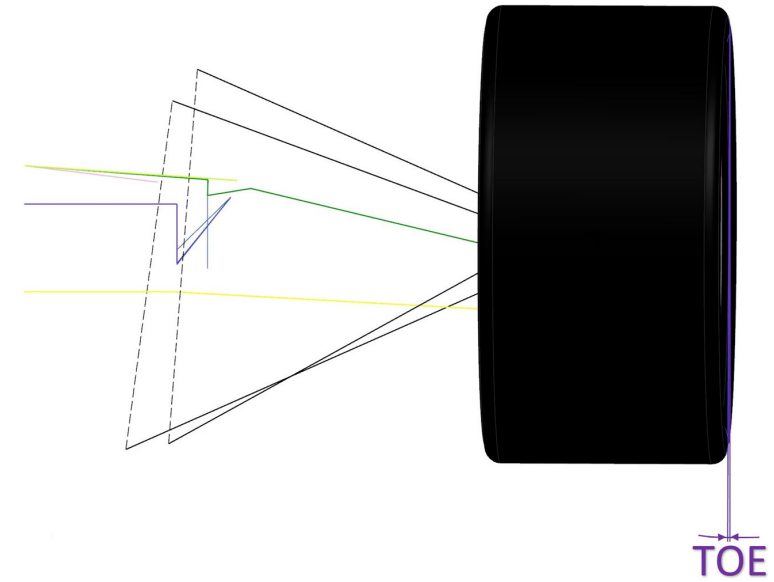

Fig. 2. Parametric model of front suspension with toe in angle 


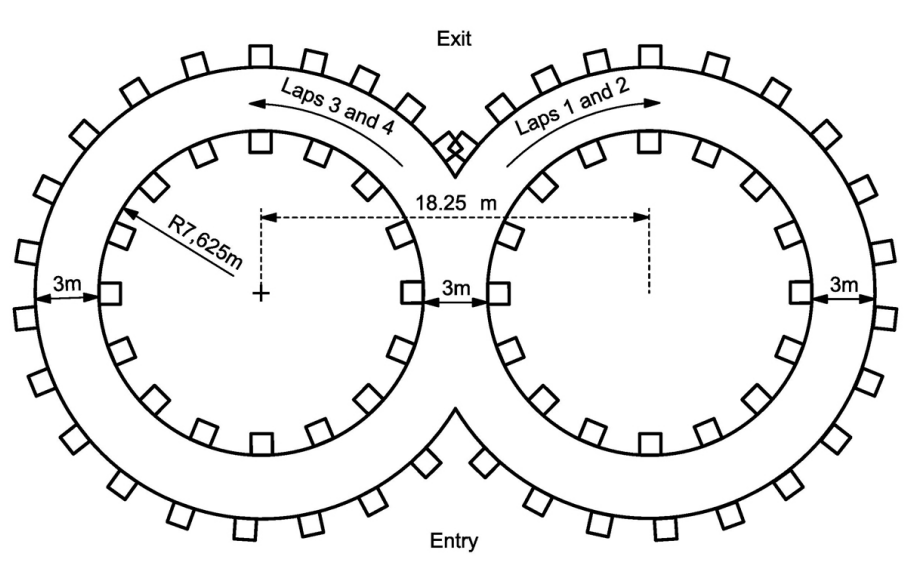

Fig. 3. FSAE skid-pad test geometry [9]

includes the dynamic analysis. As the dynamic testing data was unavailable, it was assumed that the magnitude of the forces resulting from quasistatic analysis will include the safety coefficient of 2 for the parts manufactured from both aluminum and steel alloys. Other approaches to force determination, together with validation, were presented in [8]. The parameters chosen for the front and rear axis were shown in Table 3.

Following the determination of the parametric model and the limiting forces, the calculation the CAD model was carried out. In order to manufacture the components, the technical documentation was prepared and the manufacturing processes shown in Table 4 were implemented. Additionally, the steering system consists of a steering pinion (geared type) at the front axle.

\section{Measurements}

The main goal of the tests was to observe the influence wheel travel on both camber and toe in angle as well as shock absorber spring deflection. The tests were conducted using the Longacre products.

\section{Test environment}

The main requirement for the testing environment was to perform the test on a flat and even surface in order to obtain unbiased results. This was realized by placing the vehicle in one of the faculty halls, where the ground flatness was sufficient. Furthermore, all the testing equipment had to be leveled w.r.t the ground surface. In order to introduce loads into the system, multiple elements of known mass were placed at the driver seat location. For the computer model, the NX Unigraphics motion module was used.

\section{Camber and toe in angles measurements}

The measuring method was shown in Figure 6 and Figure 7. The camber angle equipment had to be calibrated w.r.t the ground level first in order to obtain the correct results. In order to obtain the values of toe in angle, both the laser measuring equipment and the geometrical methods were utilized.

\section{Determination of wheel steering angle}

This value was measured as a function of relative steering pinion position. A set of turning plates and calipers was used for the measurements (Fig. 8).

\section{Determination of shock absorber length and vertical position of characteristic point}

In order to measure the first value, a set of calipers was used. Prior to measuring the deflection, all the shock absorbers were set to the same length at front and back of the vehicle. In order to obtain the vertical point position (Fig. 9) both measuring tape and caliper set were used for the front and rear.

\section{Weighing system and loads}

In order to obtain even load increase, a set of ten rubber plies was used. The average weight of one ply was equal to $0.5 \mathrm{~kg}$. The weight acting on each wheel was recorded using computer scales placed under the tires. 
Table 2. Input data for quasi-static calculations performed in [5]

\begin{tabular}{|c|c|c|c|c|}
\hline \multicolumn{5}{|c|}{ Input } \\
\hline \multirow{3}{*}{ Dim. } & \multicolumn{2}{|l|}{ Wheel base } & 1550 & \multirow{3}{*}{$\mathrm{mm}$} \\
\hline & \multicolumn{2}{|l|}{ Front track } & 1200 & \\
\hline & \multicolumn{2}{|l|}{ Rear track } & 1200 & \\
\hline \multirow{18}{*}{$\begin{array}{l}\text { Mass and } \\
\text { inertia }\end{array}$} & \multicolumn{2}{|l|}{ Total mass } & 330.00 & $\mathrm{~kg}$ \\
\hline & \multicolumn{2}{|l|}{ Total Mass distribution } & 48.00 & $\% \mathrm{Fr}$ \\
\hline & \multicolumn{2}{|l|}{ Front non suspended mass (per wheel) } & 12.00 & $\mathrm{~kg}$ \\
\hline & \multicolumn{2}{|l|}{ Rear non suspended mass (per wheel) } & 12.00 & $\mathrm{~kg}$ \\
\hline & \multicolumn{2}{|l|}{ Non suspended mass weight distribution } & 50.00 & $\% \mathrm{Fr}$ \\
\hline & \multicolumn{2}{|l|}{ Total mass CG height } & 315 & \multirow{3}{*}{$\mathrm{mm}$} \\
\hline & \multicolumn{2}{|l|}{ Front non suspended mass CG height } & 215 & \\
\hline & \multicolumn{2}{|l|}{ Rear non suspended mass CG height } & 215 & \\
\hline & \multicolumn{2}{|l|}{ Suspended mass } & 282.00 & $\mathrm{~kg}$ \\
\hline & \multicolumn{2}{|l|}{ Suspended mass weight distribution } & 47.66 & $\% \mathrm{Fr}$ \\
\hline & \multirow{3}{*}{ Suspended mass CG coordinates } & $x$ & 806.00 & \multirow{3}{*}{$\mathrm{mm}$} \\
\hline & & $\mathrm{Y}$ & 0.00 & \\
\hline & & Z & 332.02 & \\
\hline & \multirow{3}{*}{ Pitch Center coordinates } & $x$ & 923.40 & \multirow{3}{*}{$m m$} \\
\hline & & $Y$ & 0.00 & \\
\hline & & $Z$ & 114.80 & \\
\hline & \multicolumn{2}{|l|}{ Suspended mass roll inertia (ref SM CG) $-I_{x x}$} & 8.76 & $\mathrm{~kg} \cdot \mathrm{m}^{2}$ \\
\hline & \multicolumn{2}{|l|}{ Suspended mass pitch inertia (ref SM CG) - I } & 18.89 & $\mathrm{~kg} \cdot \mathrm{m}^{2}$ \\
\hline \multirow{8}{*}{$\begin{array}{c}\text { Spring ARB } \\
\text { Tire }\end{array}$} & Front spring stiffness & & 24.43 & $\mathrm{~N} / \mathrm{mm}$ \\
\hline & Rear spring stiffness & & 25.78 & 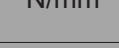 \\
\hline & Front SM Damping ratio @wheel & & 1.758001 & \\
\hline & RearSM Damping ratio@wheel & & 1.698142 & \\
\hline & Front ARB stiffness & & 177.63 & $\mathrm{~N} / \mathrm{mm}$ \\
\hline & Rear ARB stiffness & & 61.63 & $\mathrm{~N} / \mathrm{mm}$ \\
\hline & Front tire stiffness & & 100.00 & $\mathrm{~N} / \mathrm{mm}$ \\
\hline & Rear tire stiffness & & 120.00 & $\mathrm{~N} / \mathrm{mm}$ \\
\hline & Front spring motion ratio & & 0.965 & $\mathrm{~mm} / \mathrm{mm}$ \\
\hline P R & Rear spring motion ratio & & 0.921 & $\mathrm{~mm} / \mathrm{mm}$ \\
\hline Min. & Front anti roll bar motion ratio & & 3.007 & $\mathrm{~mm} / \mathrm{mm}$ \\
\hline & Rear anti roll bar motion ratio & & 2.084 & \\
\hline Roll & Front roll center height & & 20.00 & $\mathrm{~mm}$ \\
\hline Roil & Rear roll center height & & 40.00 & $\mathrm{~mm}$ \\
\hline & Down Force Coefficient & & 2.5 & - \\
\hline & Down Force Distribution & & 68 & $\% \mathrm{Fr}$ \\
\hline Aern & Air Density & & 1.2255 & $\mathrm{~kg} / \mathrm{m}^{3}$ \\
\hline Aero & Frontal Area & & 1.4 & $\mathrm{~m}^{2}$ \\
\hline & Speed & & 80 & $\mathrm{~km} / \mathrm{h}$ \\
\hline & Total Down Force & & 107.96 & $\mathrm{Kg}$ \\
\hline & Case to & & & \\
\hline & Lat G & & 1.00 & G \\
\hline
\end{tabular}

\section{RESULTS AND DISCUSSION}

The results from both the computer and real model were compared in the following charts. The data was collected across a wide range of wheel travel for the CAD model, yet such range was unobtainable for the real model. It is due to the ground clearance and means of test method, where the shock absorber deflection was forced by applying load on the vehicle. The starting point is the car neutral position and the end point are the state where vehicle is loaded with $200 \mathrm{~kg}$. This represents more realistic operation of a vehicle, as the addition of mass is somehow comparable to an increase of downforce coming from the 
Table 3. Front and rear axis parameters

\begin{tabular}{|l|c|c|}
\hline \multicolumn{1}{|c|}{ Parameter } & Front axis & Rear axis \\
\hline Camber angle & $-2,8^{\circ}$ (regulated by washers) & $-1^{\circ}$ (regulated by washers) \\
\hline Caster angle & $5^{\circ}$ & $5^{\circ}$ \\
\hline KPI-King pin inclination & $6^{\circ}$ & $5^{\circ}$ \\
\hline Toe in angle & $-2.8^{\circ}$ (regulated by thread) & $-0,25^{\circ}$ (regulated by thread) \\
\hline Mechanical trial & $25 \mathrm{~mm}$ & $15 \mathrm{~mm}$ \\
\hline Front track & $1200 \mathrm{~mm}$ (regulated by washers) & $1200 \mathrm{~mm}$ (regulated by washers) \\
\hline Scrub radius & $38 \mathrm{~mm}$ & $30 \mathrm{~mm}$ \\
\hline Roll center & $20 \mathrm{~mm}$ & $55 \mathrm{~mm}$ \\
\hline
\end{tabular}

Table 4. Manufacturing processes used in suspension production

\begin{tabular}{|l|l|}
\hline Part & Manufacturing technology \\
\hline Wheel hub & CNC lathe \\
\hline Knuckle & CNC machining \\
\hline Braking disc & Water cutting \\
\hline $\begin{array}{l}\text { Lower and upper wishbone } \\
\text { A arms) }\end{array}$ & Welding \\
\hline Steering rod & Welding \\
\hline Push rod & Welding \\
\hline Rocker & Water cut metal sheets, \\
\hline Shock absorber & Turned bushing, welding \\
\hline Braking caliper & Bought \\
\hline Bearing nut & Bought \\
\hline Plain bearing/sliding bearing & Bought \\
\hline Distance washers & Laser cutting \\
\hline
\end{tabular}

aerodynamic package, yet could potentially influence the results.

The range was not extended towards the negative values as lifting the vehicle could lead to uneven height distribution. The models were compared across this narrow range of real model. However, the full range of data was shown for the computer model to present the expected trend.
The results of camber and toe in angles determination.

The change of the front camber angle can be assumed as a linear function, yet its slope does not match the theoretical value (Figure 10). Whether it is a fault of the manufacturing processes is unknown, as the compliance of a tire could play significant role in angle measurements. The results obtained for the rear wheel were assumed as inconclusive. The accuracy of the measuring device did not allow for the measurements with the precision required to obtain the valid slope.

Lastly, the change of toe in angle was nonlinear with the lowest value being equal to 1.775 degree for the wheel travel of $18 \mathrm{~mm}$. This is the most interesting finding of this experiment as it would suggest that there is significant difference between the computer and real model.

\section{Results of steering angle determination}

This time, the whole range of motion for both real and computer model could be measured (Figure 13). What is interesting is that the range of real steering pinion displacement is a few millimeters shorter than the modeled one. It is due

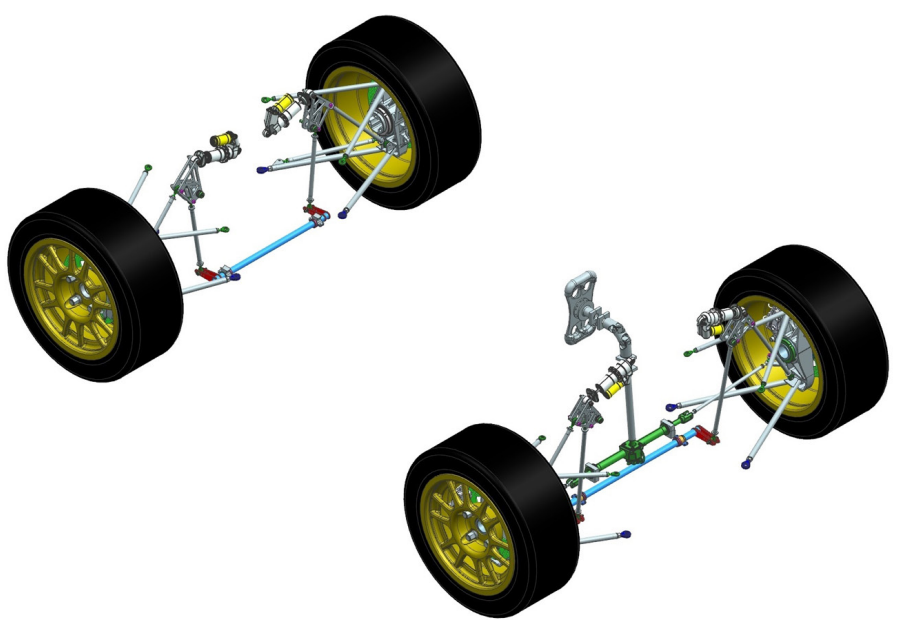

Fig. 4. CAD model of the suspension system 


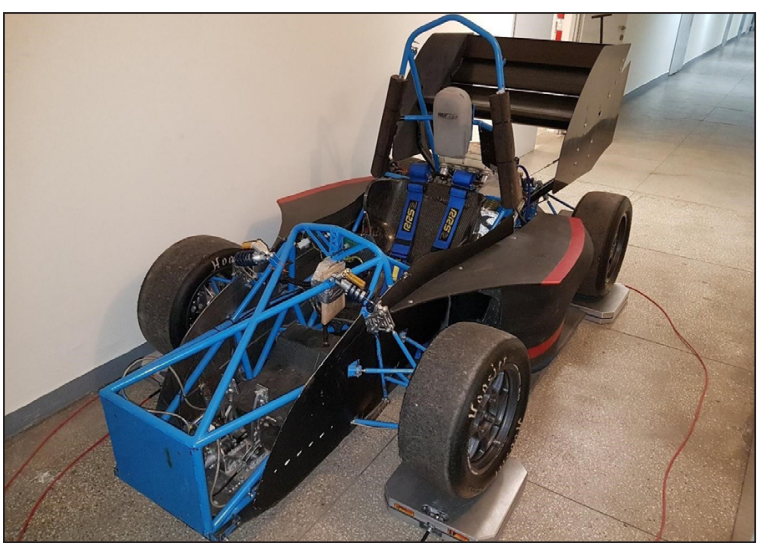

Fig. 5. Real model of the vehicle

to the inaccuracy in placing the restrainers during the vehicle manufacturing. The steering angles of a wheel for positive values of steering pinion deflection were different by about $10-20 \%$. Additionally, there was a visible bias (the steering angle for zero deflection of a pinion was positive) in the computer data as the wheel had initial toe in

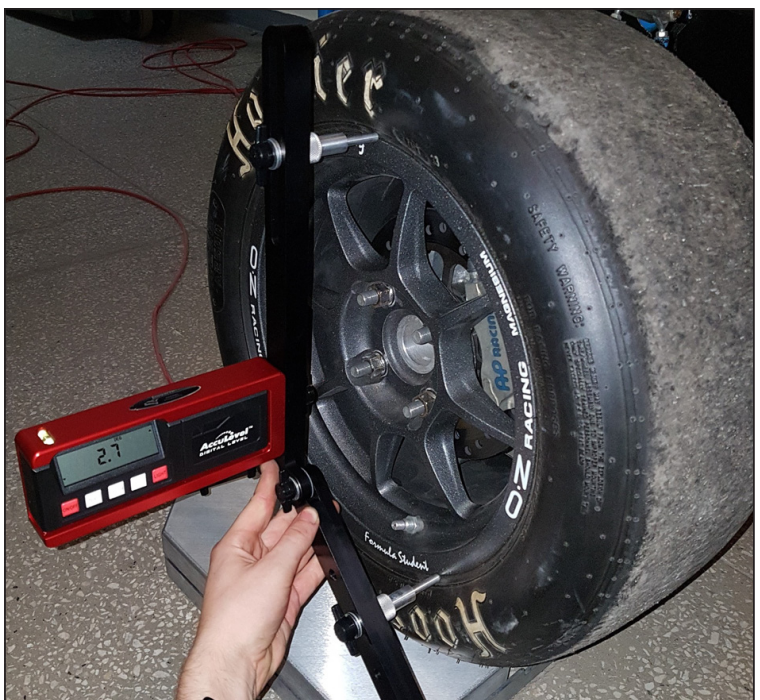

Fig. 6. Measurement of camber angle

angle which is measured as a steering angle. Additionally, the angle projection is $3 \mathrm{D}$, which adds camber angle of the front wheel to the initial bias of the data.

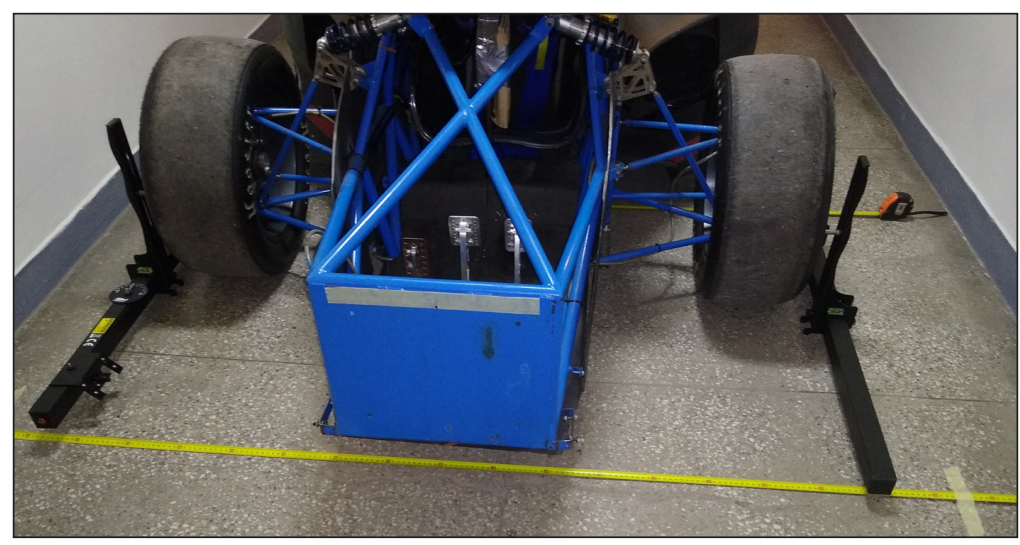

Fig. 7. Measurement of toe in angle using both laser and geometrical

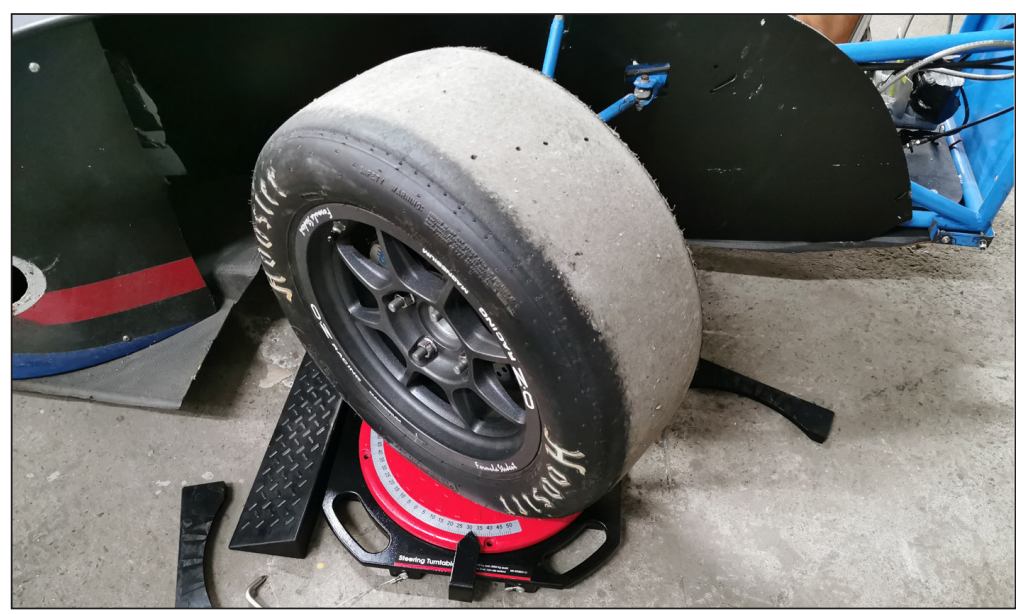

Fig. 8. Measurement of steering angle using turning plates 


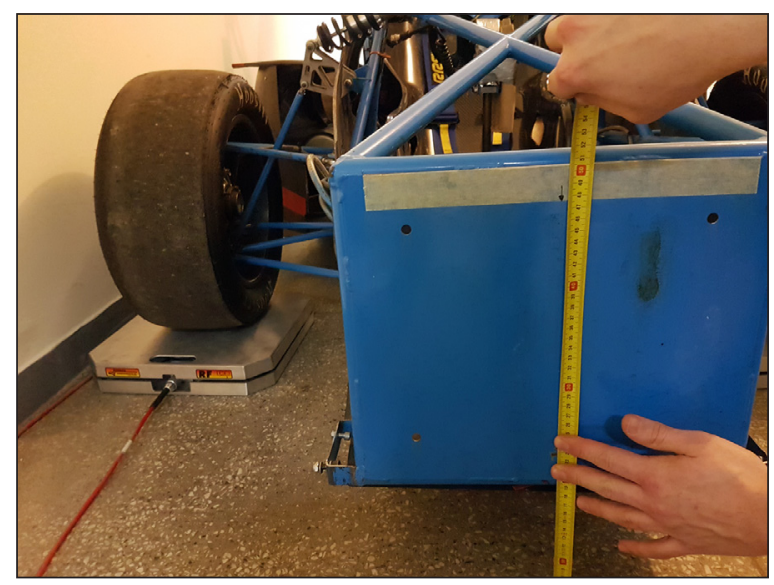

Fig. 9. Measurement of the front characteristic point position

\section{Results of shock absorber spring deflection and vertical position of characteristic point determination}

Both characteristics can be assumed as linear ones (Figure 14 and Figure 15). The characteristics for the real model were obtained as a function of load, yet in order to compare them to the computer model the deflection of a spring will be a function of the wheel travel (i.e. the characteristic point). The mass influence on shock absorber deflection was also recorded. The difference between the maximum value (unloaded vehicle) of shock absorber compression length at the front left wheel and the minimum position (maximum load) was equal to $16.06 \mathrm{~mm}$ and the corresponding change of load was equal to $67.7 \mathrm{~kg}$. For the case of the rear left wheel, the change of length was equal to $9.4 \mathrm{~mm}$ and the load change was $38.7 \mathrm{~kg}$. The change of the vertical position of characteristic point at the front between minimum and maximum load conditions was equal to $26 \mathrm{~mm}$ for the load change of $135 \mathrm{~kg}$ acting on the front axis. The corresponding value in the rear was equal to $12.76 \mathrm{~mm}$ for the load change of $80 \mathrm{~kg}$.

\section{CONCLUSION}

The comparison of two models showed that there is difference in the key design parameters. This is especially visible in the case of toe in angle (Figure 12) and camber angles (Figure 10 and Figure 11). For the first parameter, the values obtained in real model were highly non-linear, which differs significantly from the behavior predicted in the computer model. The second set of parameters (camber) show linear trend, yet their values and first derivatives do not match the design model. Other results also proved a similar trend. Whether it is caused by faulty or inaccurate manufacturing process, cannot be answered unambiguously. In order to understand why, the question of measurements accuracy must be addressed. The precision of the results was insufficient due to the following factors:

1. The measuring equipment used has insufficient resolution to measure the exact values accurately. This can be seen especially in the case of the rear camber angle (Figure 11) where the measured values change by 0.1 in the tested range, which is also the minimum threshold of the measuring device.

2 . The measuring devices mounting system is far from optimal, which can produce random errors in case of improper device fixture. As the

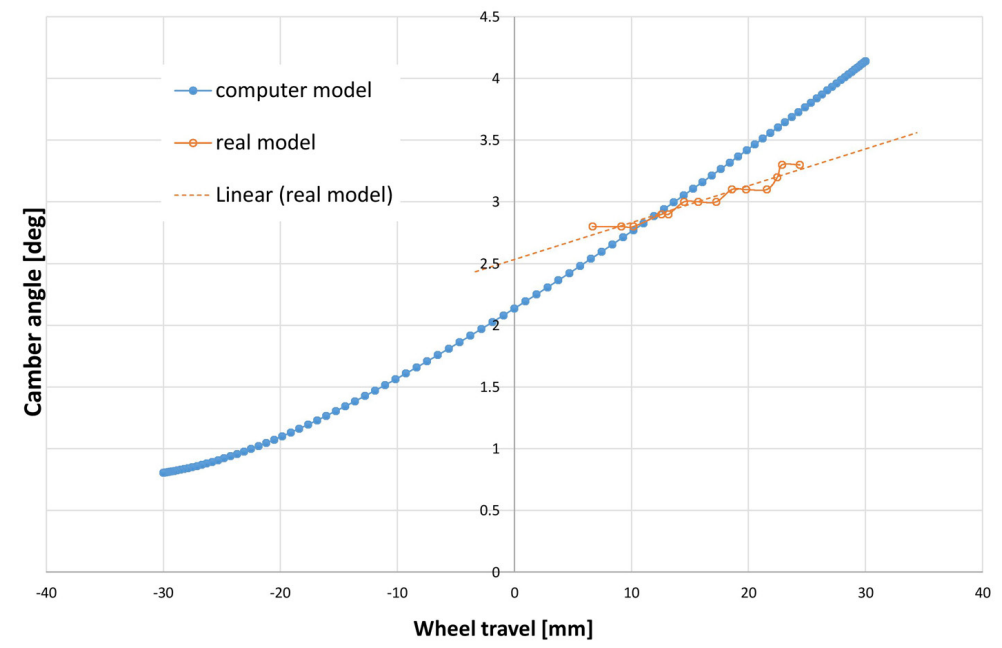

Fig. 10. Change of camber angle at the front wheel as a function of the front wheel travel 


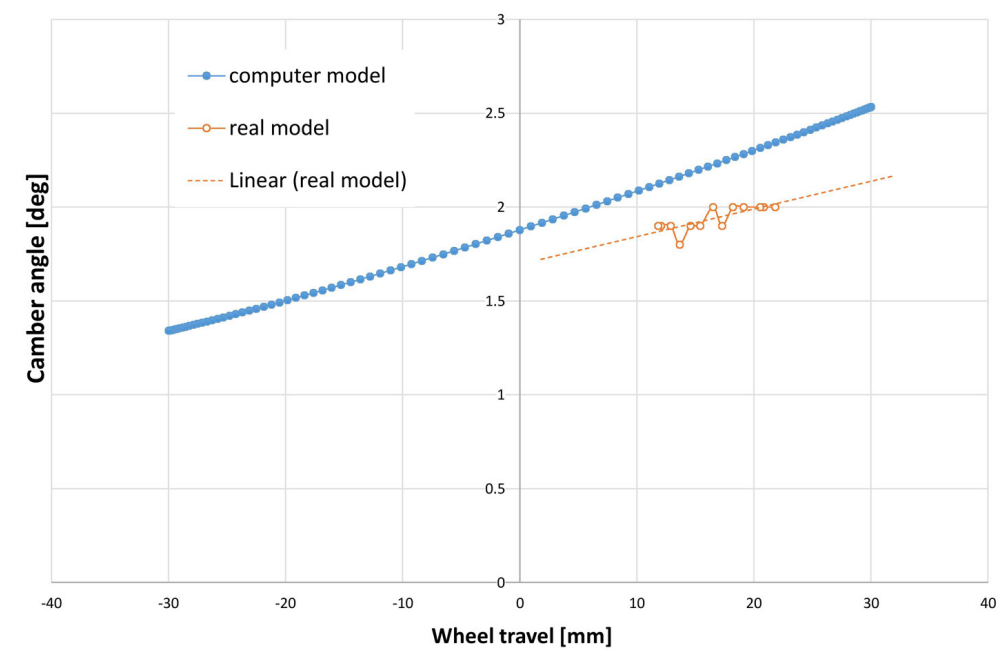

Fig. 11. Change of camber angle at the rear wheel as a function of the rear wheel travel

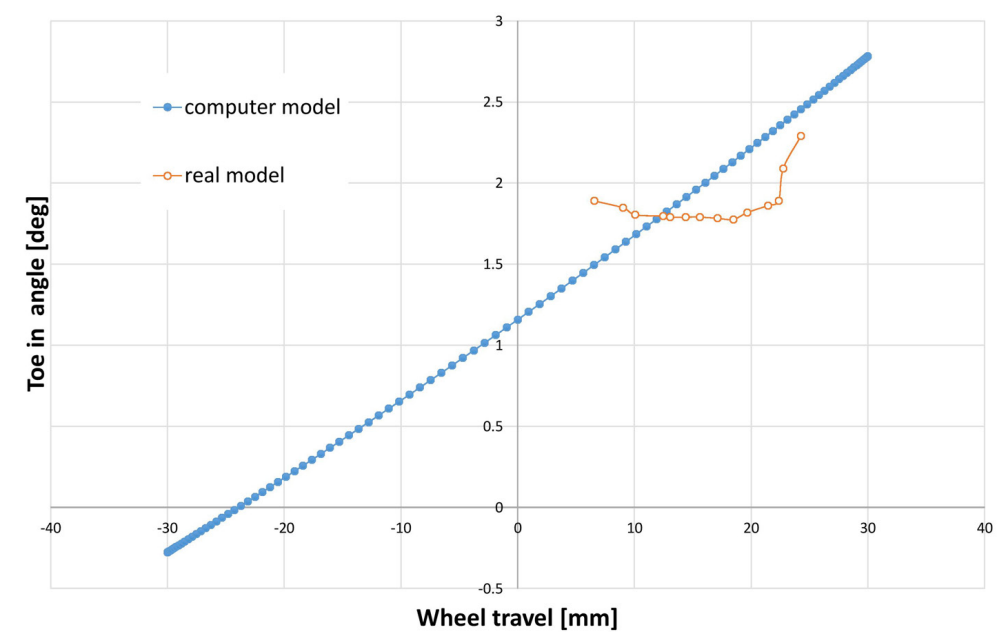

Fig. 12. Change of toe in angle of the front wheel as a function of the front wheel travel

measuring devices need to be positioned and re-adjusted for each data point, the chance of random error increases.

3. The small data sample in the case of the steering angle measurements. This is more of an author's mistake, yet since the computer model was biased, the test would be inconclusive anyway (Figure 13).

4. Tire compliance (that is static friction between ground and rubber) which could influence most of camber and toe in angle measurements.

Those factors lead to the conclusion that the accurate determination of key parameters using affordable equipment is not possible due to its accuracy. It can be improved with some modifications which will be introduced for the future tests.

However, in the case of measurements performed without the electronic devices, i.e. the results of motion ratio validation (i.e. ratio of wheel travel to shock absorber spring deflection shown at (Figure 14 and Figure 15) which show that the values of computer and real models are different. This suggests that the manufactured model has different properties than the designed one. This is quite important from a point of setting up the car in dynamic testing, the values were always set according to the theoretical model.

In order to validate the parameters on the newly built vehicle WUT3, all test performed in the future will include:

1. Testing on a marking-out table to ensure the flatness of the testing environment. The surface of testing environment used in this research was relatively flat, but from in terms of the measurement method, the ground flatness should have been controlled or known. 


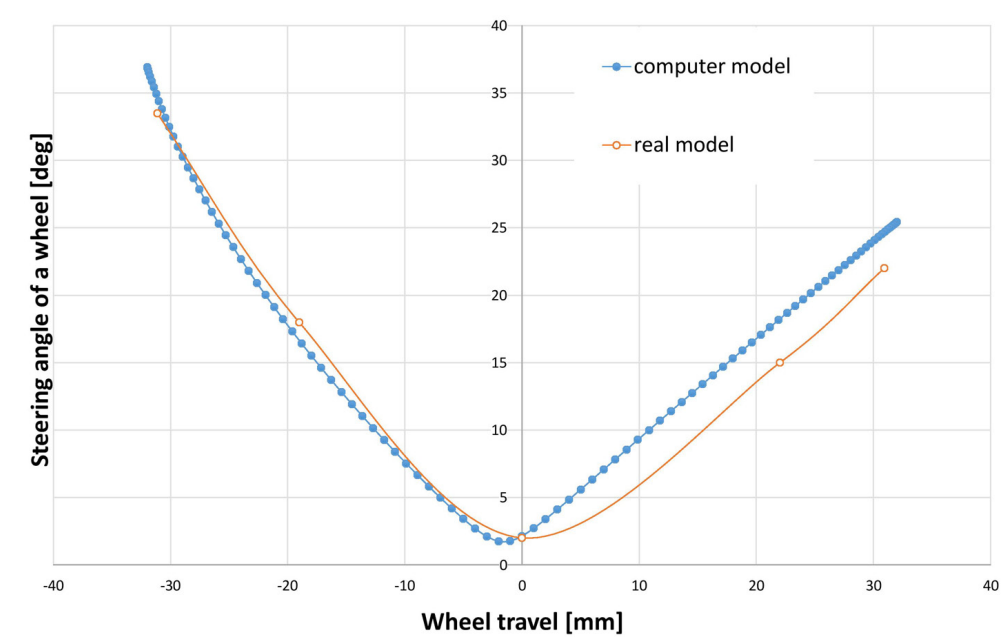

Fig. 13. Steering angle of the wheel as a function of steering pinion relative displacement

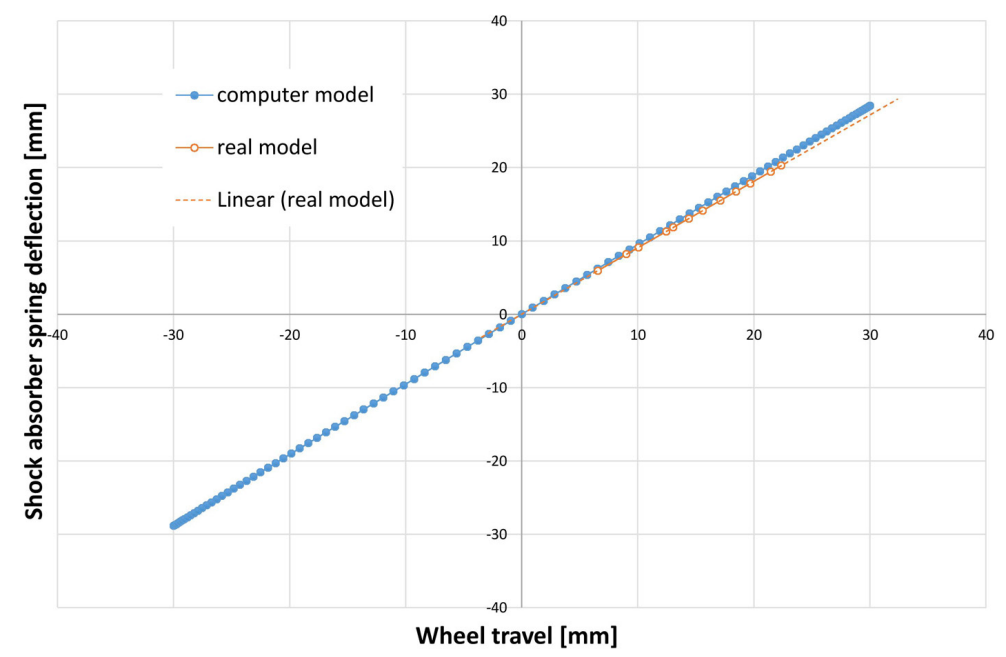

Fig. 14. Front shock absorber spring deflection as a function of front wheel travel

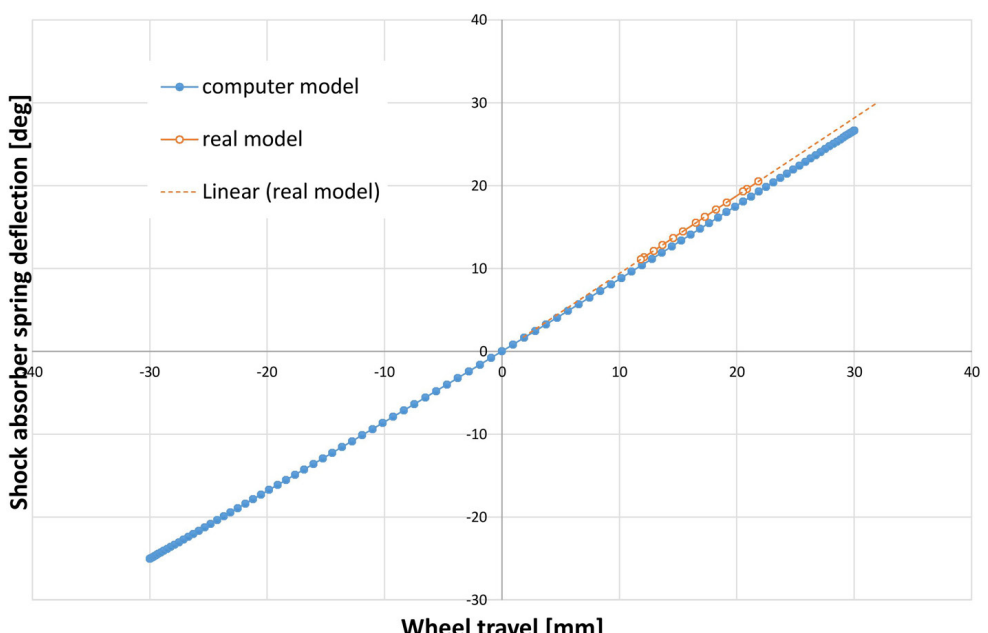

Fig. 15. Rear shock absorber spring deflection as a function of rear wheel travel 
2. Placing the vehicle on turning plates in order to measure the camber and toe in angle without the problems with tire compliance, where the friction between rubber and the ground could prevent the tire from adjusting to a new angular position. Alternatively, lubricant or sliding bearing should be used.

3. Mounting the measuring devices semi-permanently to the wheels. This can improve the chances of avoiding the random error occurring during every single re-adjustment of the device.

4. The method of changing the shock absorber spring length should be realized by replacing the shock absorber with a roman screw. This would allow collecting the data across a wider range of data and take out the friction in shock absorber. Additionally, it abandons adding weight as the method of imposing the spring length change, which is realistic, but different from the computer model.

Creating accurate vehicle behavior will help to replicate its parameters in a simulator, which currently would have to be based on the computer model only. Additionally, it will allow for better dynamic testing.

\section{REFERENCES}

1. Chang, I., Kim, N., Lee, D. (2010). Designing and manufacturing of Formula SAE-Hybrid racecar for a new engineering education program. IEEE Vehicle Power and Propulsion Conference. Lilie.
2. Leibler, K. (1959). Zastosowanie metod fizycznych w badaniach technicznych: (przyrządy i metody pomiarowe). Warszawa: PWN.

3. Li, J., Yu, S., Zhang, N., He, H., Yang, Z., Jia, Y. (2013). Formula SAE Racecar Suspension System Design. Applied Mechanics and Materials, 416-417, 1840-1844.

4. Milliken, D. (2003). Race car vehicle dynamics: Problems, answers and experiments. Warrendale: SAE International.

5. Optimum G. (n.d.). Spreadsheet for quasi-static calculations obtained as a part of training materials at OptimumG seminar, Cracov 2018.

6. Pacejka, H. (2006). Tyre and Vehicle Dynamics.

7. Pasecki, E., Hirszberg, L. (1978). Metody pomiarowe (Laboratorium elektronicznych układów pomiarowych: praca zbiorowa Cz.3). Gliwice: Politechn. Śląska.

8. Rui, R., Gong, B., Fang, Z. (2019). Force and strength analysis of FSAE racing suspension based on spatial analytic geometry. Journal of Physics: Conference Series: Materials Science and Engineering, 612 .

9. SAE. (2020). FSAE Rules 2020. Retrieved from https://www.fsaeonline.com/cdsweb/app/NewsItem.aspx? NewsItemID $=2 \mathrm{c} 1 \mathrm{ab} 552-40 \mathrm{c} 3-4 \mathrm{~b} 97$ a258-582dca0ea505

10. Saurabh, Y.S., Kumar, S., Jain, K.K., Behera, S.K., Gandhi, D., Raghavendra, S., Kalita, K. (2016). Design of suspension system for formula student race car. Procedia Engineering, 144, 1138-1149.

11. Tumański, S. (2016). Technika pomiarowa.

12. Zaidie, M., Hashim, I., Tasyrif, N., Basha, A., Ibrahim, I., Kamaruddin, N.S., Shahriman, A.B. (2017). Analysis of a front suspension system for UniART FSAE car using FEA. Journal of Physics: Conference Series, 908. 